\title{
Die roeping van die onderwyser in die verbondsonderrig
}

\author{
A.J. van Rooy \\ PRETORIA
}

\section{Die onderwys in die sewentiende eeu}

Gedurende die sewentiende eeu het die Europese regerings in 'n besondere verhouding tot die kerke gestaan. In sommige lande was die Rooms-Katolieke kerk en in ander lande sekere Protestantse kerke die dominerende kerkgroepering. Skeiding tussen kerk en staat was feitlik onbekend. Die regerings het sowel die godsdiens as die onderwys bevorder en ondersteun. In die Protestantse lande het die regerings juis die Refonnatoriese kerke gebruik om skole te stig, daaroor toesig te hou en die onderwys te bevorder

Nederland was die wêreld op die gebied van die volksonderwys voor. Die Christelike dagskole wat deur die regering beskerm en ondersteun is, was reformatories, ofskoon die Roomse en die humanistiese kragte ook aan die werk was.

Sommige ouers het nie besef dat hulle kinders skoolonderwys nodig gehad het nie. Aangesien hulle nie die belangrikheid van deeglike Christelike onderwys ingesien het nie, het hulle in gebreke gebly om te organiseer en skole te open.

Enkele onderwysers het wat leer en lewe betref, nie aan die Reformatoriese verwagtings voldoen nie. Aangesien besef is dat die ware welsyn van die kerke grotendeels van die skole afgehang het, het sinodes kerkrade gemaan om getrou en waaksaam te wees. Die kerke het met die goedkeuring van die regering sekere maatreëls getref. Dit het byvoorbeeld verpligtend geword dat die onderwysers die Refonnatoriese geloof sou bely, lidmate van die Reformatoriese kerke sou wees en dat hulle in hulle gedrag godvrugtig sou wees. Ook is van hulle verwag om die Reformatoriese belydenisskrifte te onderskryf. Hulle moes bewys dat hulle die kategismus ken en dat hulle dit op skool kon onderrig (Van Dellen, 1969: 272-3).

\section{Die Sinode van Dordrecht 1618-1619}

Hierdie sinode het 'n ekumeniese karakter gehad, aangesien Duitse, Engelse, Nederlandse en Switserse afgevaardigdes teenwoordig was. Die sinode is byeengeroep om aan die afwykende leerstellings van die Remonstrante aandag te 
skenk. Vyftien Remonstrantse predikante is uitgenooi om voor die sinode te verskyn. Aangesien hulle nie dadelik beskikbaar was nie, het die sinode intussen met ander werksaamhede voortgegaan (Los, 1911:203).

Daar is aanbeveel dat huis-, skool- en kerklike katkisasie gehou word en dat die drie instansies saamwerk.

* Die ouers is gemaan om vir hulle kinders huiskatkisasie te hou.

* Van die onderwysers is verwag om die kinders die Kortbegrip en die Kategismus te leer en te verklaar.

* Die leraars en die kerkrade is verplig om streng toe te sien dat die leer gehandhaaf word.

'n Formulier is vasgestel om deur predikante, professore en skoolmeesters onderteken te word. Daardeur sou die gemeentes 'n waarborg verkry dat hulle kinders deur gereformeerde manne onderrig word.

Die sinode het ook die belangrikheid van tersière onderwys besef. In Nederland was reeds drie inrigtings wat elk as hogeschool bekend gestaan het, naamlik dié te Leiden, Franeker en Groningen. Na die sinode is in die jaar 1632 te Amsterdam 'n "doorluchtige school" geopen, die latere gemeentelike universiteit. Vier jaar later is 'n verdere hogeschool te Utrecht gestig wat met Voetius as professor beroemd geword het (Los, 1911:206-207).

\section{Die Dordtse Kerkorde}

'n Besluit wat reeds in die jaar 1586 deur 'n Nederlandse sinode geneem is, het 32 jaar later artikel 21 van die Dordtse Kerkorde geword:

Die kerkrade moes oral toesien dat daar goeie onderwysers is wat die leerlinge niet alleen leeren lesen, schrijven, spraken ende vrije consten, maar oock deselve in der Godsaligheyt ende in den Catechismo onderwijzen (Postma, 1935:317).

Dit is opvallend dat die terme kerk en skool nie in hierdie kerkorde-artikel voorkom nie; die nadruk het op die persoonlike verantwoordelikheid geval. Waar na kerkrade verwys is, het die verantwoordelikheid by die bedienaars van die Woord en die ouderlinge gelê - húlle moes toesien dat daar goeie onderwysers met die nodige bekwaamheid is.

Die goeie samewerking tussen die regering en die kerkrade het meegebring dat die bedienaars van die Woord en die ouderlinge die leer en die lewe van die onderwysers veral met huisbesoek in oënskou moes neem. Die skole self is onder die beheer en toesig van die betrokke onderwysowerhede gelaat. Dit was nie nodig dat die kerkrade onderwysers oplei nie. Daar was reeds inrigtings vir 
tersiêre onderwys wat die nodige kon doen. Die onderwysers het ook in die kategese 'n belangrike taak gehad.

\section{Die onderwys in Suid-Afrika}

Met die koms van Jan van Riebeeck en sy metgeselle in 1652 was die Dordtse Sinode, 33 jaar vantevore, nog vars in die geheue. Aanvanklik het veral die sieketroosters naas hulle herderlike werk ook die onderwys behartig.

Van Riebeeck het gehoop dat die Hollandse volksplanting aan die Kaap die middel in die hand van God mag wees om die heidene tot die Christelike gereformeerde leer te bring. Dic ou gereformeerdes het immers by niemand in hulle sendingywer agter gestaan nie. Selfs gedurende die Remonstrantse twiste het hulle hulle sendingplig nooit vergeet nie (Du Toit, 1911:297).

Dit was baie moeilik on die Hottentotte aan Christelike en beskawingsnorme gewoond te maak. Spoedig was daar in Kaapstad 'n skool vir die slawe van die Kompanjie waarin hulle nie alleen in lees en skrywe onderrig is nie, maar ook in die Bybel, Heidelbergse Kategismus en die gebedskuns - getrou aan die Dordtse tradisie. Wanneer hulle taak afgehandel is, sou elkeen ' $n$ "glaasje brandewijn en twee duimen tabak ontvangen" (Du Toit, 1911:209).

\section{Die sending en die onderwys}

Onder die leiding van die Piëtiste en Metodiste het aan die einde van die agtiende eeu opwekkingsdienste, verenigings en broederskappe ontstaan, en is voortdurend tot sendingswerksaamheid aangemoedig. Hierdie 'nuwere sending' was niekerklik, is deur genootskappe buite die kerk om bedryf en was ook nie gereformeerd in aanslag nie (Du Toit, 1911:310).

Die sendelinge was jarelank (tot 1907 en selfs tot 1953) die enigste voorsieners van onderwys aan swart mense. Staatsondersteuning het langs die weg van sendelinge-onderwys geskied (Van der Walt, 1992:82). Dit was die sendelinge wat sommige swart tale in geskrewe vorm bestendig het, veral wat die vertaling van die Bybel betref. Reeds in 1857 is die Bybel in Tswana vertaal.

Die sendelinge was die eerste om skole op te rig en geleerdheid aan swart mense te verskaf. Teen 1850 het ongeveer 9000 swart mense onderrig ontvang, 100000 in 1900 en 170000 in 1909. Inrigtings soos Lovedale en Fort Hare in Kaapland, Adams Kollege in Natal en Kilnerton in Tranvaal het hoër onderwys verskaf waar ' $n$ middelklas intellektuele swart elite in die beginsels van die Christendom, Westerse beskawingswaardes en die liberale denke opgevoed is.

Geleerdes wat hierdie sendingskoling ondergaan het, was onder andere J.M. Soga, S.M. Molema, A.B. Xuma, Z.K. Matthews, S. T. Plaatje, John Dube en J.T. 
en D.D. Jabavu - 'n geslag wat tot ongeveer die Tweede Wêreldoorlog leiding gegee het. Uit hulle geskrifte blyk politieke gematigheid, rasseverdraagsaamheid, aanvaarding van die Westerse leefwyse en Christelike beginsels, maar ook konstitusionele versetmetodes soos dié van blanke liberale leiers, veral van die "Cape Liberalism". Hulle het as ideaal gestel die opvoeding van swartes tot op 'n gelyke vlak met die blankes (Van Jaarsveld, 1984:124).

\section{Die Potchefstroomse Sinode van die Gereformeerde Kerke, 1869}

Tydens hierdie sinode is besluit om 'n teologiese skool met die volgende doelwit te stig:

Die Sinode besluit dat die kweekskool te Burgersdorp so ingerig sal word dat daar nie alleen predikante opgelei sal word nie maar ook jongelinge wat hulle bekwaam vir onderwysers van die jeug, ja ook jongeliede wat sonder bestemde doel studeer, geleentheid sal hê om volgens hulle vatbaarheid gebruik te maak van die skool ... (Jooste, 1958:114).

Op die voetspoor van Dordt het die kerkrade (in sinode vergader) toegesien dat daar goeie onderwysers sou wees wat die leerlinge ook in die kategismus en die godsdiens kon onderrig. Die saadjie wat hier gesaai is, het met die seën van die Here mettertyd wasdom bereik in die Potchefstroomse Universiteit vir Christelike Hoër Onderwys met sy spreuk "In U lig" (Ps. 36:10) saam met die Teologiese Skool.

\section{President S.J.P. Kruger}

Met sy inswering as staatspresident op 12 Mei 1898 het president Kruger in sy toespraak hom ook tot die onderwysers gewend:

Wanneer u, Meesters en Meesteresse, die geloof nie ken nie, hoe sal u dan die kinders deur die geloof na Christus bring? Ek vertrou egter dat $u$ dit ken en vergeet dus nooit om deur die geloof die kinders tot die Heer te bring nie en waak daarteen dat die godsdiens nie na die agtergrond kom en slegs wetenskappe geleer word nie, want dan tas u die godsdiens aan en dit word vergeet (Postma, 1935:312). (Vry vertaal uit die Nederlands.)

Dit is duidelik dat president Kruger die onderwysers aan dieselfde roeping as deur die Sinode van Dordrecht gestel, wou onderwerp. Hy het in samewerking met die superintendent van onderwys, ds. S.J. du Toit en sy opvolger dr. N. Mansvelt, probeer om die onderwys daarvolgens in te rig.

Die leidende geeste om hierdie ideaal te verwesenlik, was Hollanders wat Christelik in lewensopvatting en wandel, die jong republiek met sy Calvinistiese staatshoof kragtig gesteun het. Onderwysers Dönges en Bonsma het getuig: ".. 
dit was 'n genot om onderwyser te wees en mee te werk aan die opbou van 'n jong en magtige nasie" (Postma, 1935:317).

\section{Die Kerkorde van die Gereformeerde Kerke in Suid-Afrika}

Aanvanklik het artikel 21 van die Kerkorde soos volg gelui:

Die Kerkrade moet oral toesien dat daar goeie onderwysers is wat die kinders nie alleen leer lees en skrywe en hulle in tale en ander kundighede onderrig nie, maar ook in die Godsaligheid en in die Kategismus (Du Toit, 1945:22).

In 1967 is hierdie artikel gewysig om soos volg te lees:

Die kerkrade moet toesien dat die ouers die skoolonderrig aan hulle kinders in die vrees van die Here laat geskied (Deputate, 1967:64).

Die Sinode van Dordrecht het tussen huis-, skool- en kerklike katkikasie onderskei. Die ouers, die onderwysers en die leraars (en die kerkrade) het hulle eie take in die kategese gehad. Die gewysigde artikel het die woord onderwyser heeltemal uit die Kerkorde laat verdwyn. Deur slegs skoolonderwys te noem is die belangrikheid van tersiêre onderwys heeltemal uit die oog verloor. Kerkrade sou ook nie meer direkte verantwoordelikheid vir die onderwyser as lidmaat hê nie. Daar sou slegs 'n wakende oog oor die ouers gehou word wat die skoolonderrig van hulle kinders betref.

\section{Die Christian Reformed Church van Amerika}

Aanvanklik het hierdie kerke die Engelse vertaling van die Dordtse Kerkorde gehandhaaf. Artikel 21 het toe soos volg gelui:

Everywhere consistories shall see to it that there are good schoolmasters, who shall not only instruct the children in reading, writing, languages and the liberal arts, but likewise in godliness and in the Catechism.

In 1914 is die artikel verander om soos volg te lui:

The consistories shall see to it that there are good Christian schools in which the parents have their children instructed according to the demands of the covenant.

Met die hersiening van die Kerkorde is die artikel se nommer na 71 verander en is die artikel gewysig om soos volg te lui:

The consistory shall diligently encourage the members of the congregation to establish and maintain good Christian schools, and shall urge parents to 
have their children instructed in these schools according to the demands of the covenant (Van Dellen, 1969:272).

In die Verenigde State van Amerika is nie van die owerheid verwag om op godsdienstige gebied onpartydig te wees nie, maar om neutraal te wees. Godsdiensonderrig en godsdienstige vereniginge is nie op skool toegelaat nie. Daar het 'n behoefte aan Christelike skole ontstaan en die kerkorde moes daarby aangepas word. Die kerkrade moes die ouers aanspoor om skole op te rig en te onderhou.

\section{Die taak van die ouers}

Lewe ontstaan in die midde van die huisgesin. Die biotiese aspek lê die ouers se eerste verantwoordelikheid by die huisgesin waar die kinders met liefde versorg behoort te word. Daarom is die bestemming van die huisgesin eties van aard (Henning, 1991:234).

Ouers behoort die omvang van hulle opvoedingstaak te besef, sodat hulle in die ingewikkelde leefwêreld die kind koersvas kan begelei. Hulle behoort koninkrykswerk liefdevol, spontaan en hartlik te verrig. Die verbond behoort so aan hulle kinders verduidelik te word dat hulle vas en seker aan God se sorgsaamheid en liefdestrou kan glo. Hulle moet met vertroue, vreugde en blymoedigheid die erns van Gods trou besef (Bamard, 1992:3).

\section{Die taak van die onderwyser}

'n Skool word gestig om 'n kultuurvormende mag te wees; daarom is die skool histories gefundeer en word die kind tot analitiese denke opgevoed. 'n Skool is wesenlik nie ' $n$ huisgesin nie, en 'n huisgesin is nie ' $n$ skool nie, ofskoon hulle die gemeenskaplike belang in die opvoeding van die kind het (Henning, 1991:232-4).

Sonder goeie voorligting sal die verhouding tussen ouers en onderwysers grotendeels op aanvoeling berus en nie op grondliggend opvoedkundige beginsels nie. Soms is daar maar net 'n vae idee van die wyse waarop onderwysers en ouers doelgerig met mekaar behoort om te gaan. Ongelukkig gee die selfvoldaanheid van sekere skole en die burokratiese styl van skoolhoofde en onderwysers die indruk dat die skool volledig en uitsluitlik die gesagsgebied van die onderwyser is. So 'n ingesteldheid veroorsaak dat die ouers nie geesdriftig betrokke kan raak nie (Postma, 1987:253 en 260).

Die Christenonderwyser is geroepene van God, geroepe om jongmense wat na die beeld van God geskape is, te onderrig en te lei tot Christenskap op elke lewensterrein.

Elke onderwyser se lewens- en wêreldbeskouing bepaal sy opvatting van 
* God, die wêreld en homself,

* sy houding teenoor, en sy verhouding met sy leerlinge,

* die leerinhoude wat hy selekteer en beklemtoon,

* die perspektief waaruit hy die leerinhoude aanbied en

* die metode van aanbieding.

Die onderwyser is inderdaad die lewende kurrikulum vir die skool (Dreckmeyr, 1992:11-12).

\section{Die leerstof}

Daar bestaan 'n bepaalde struktuur, bouplan of wetmatige karakter in die werklikheid wat deur God as leerbaar daargestel is. Die mens word sodoende die kenner, wat die opdrag het om die kenbare deur middel van sy kenaktiwiteit te ontsluit na die wesensaard daarvan, naamlik die wette wat God daarin geskep het. Die resultaat van hierdie kenaktiwiteit is kennis as produk van gehoorsaamheid aan God (Steyn, 1987:138-139).

Alle kennis, ook dié wat op skool onderrig word, moet heenwys na God as die Oorsprong van menslike kennis. Geen vak mag onderrig word as ' $n$ versameling begrippe, feite en wette nie. Die vakinhoud moet op die alledaagse lewe self gebaseer wees en moet praktiese nut vir die lewe hê. Die natuurwetenskaplike vakke moet byvoorbeeld so aan die kind onderrig word dat hy sal besef dat die natuurwette slegs benaderde beskrywings is van wette waardeur God die skepping onderhou (Dreckmeyr, 1992:11-12).

Aardrykskunde bied byvoorbeeld genoegsame geleentheid om Bybelse beginsels aan leerlinge voor te hou. Die onderwyser kan sy Christelike lewensbeskouing toepas op die verhouding tussen die mens en die aarde in hulpbronbenutting, die praktyke van weiding, akkerbou, grondbewaring en veldbestuur en die effek daarvan op die kwaliteit van die bodem. Daaruit volg die noodsaaklikheid van sorgsaamheid, deurdagtheid en beskerning as nonns (Gouws, 1992:10).

Die omvang van die leerinhoud word bepaal deur dic beskikbare tyd en die tempo waarteen die leerders die inhoud kan bemeester (Steyn, 1987:141)

\section{Die skoolhandboeke}

J.L. van der Walt het enkele skoolhandboeke wat hy ewekansig uitgesoek het, in die lig van die vereiste vir Christelike onderwys van nader betrag

Die doelstelling wat in die Aardrykskundehandboek vir standerd 3 genoem word, is heeltemal positivisties; die hele boek toon geen gevoeligheid vir Christelike onderwys nie (Van der Walt, 1990:253) 
In die Natuur- en Skeikundehandboek vir standerd 8 kom die positivisme duidelik op die voorgrond, ofskoon daar genoeg geleentheid vir Christelike en Skrifmatige onderwys gebied word (Van der Walt, 1990:256).

Die handboek Basiese bedryfskennis st. 6 volg 'n trant wat nie noemenswaardig van die standerd 3-boek verskil nie. Ter beantwoording van die vraag 'Hoekom moet ons teken?' gee die skrywers 'n antwoord wat net sowel in enige ander handboek ter wêreld van toepassing kan wees. Van die noodsaaklikheid on te leer om tegnies te teken ter uitvoering van die kultuuropdrag van God aan die mens is hier geen sprake nie (Van der Walt, 1990:253-254).

Van der Walt het bevind dat selfs onderwysers wat in hulle opleiding aan 'n Christelike, Skrifmatige of reformatoriese aanpak ten opsigte van hulle vakke blootgestel is en daarin opgelei is, die entoesiasme vir Christelike onderwys met verloop van tyd verloor. Die onderwyser in die klaskamer gee maar toe en gee onderrig op 'n gewaande neutrale, selfs pragmatiese en positivistiese wyse (Van der Walt, 1990:225).

\section{Die opleiding van onderwysers}

Daar is reeds aangetoon dat die onderwys van die swart mense in Suid-Afrika aanvanklik deur sendelinge behartig is. Aangesien hierdie sendingonderwys van sekere genootskappe uitgegaan het, het die onderwys 'n ander grondslag gehad as dié van die Afrikaans-Refonnatoriese kerke. So was die humanisties-liberalistiese lewensbeskouing die karakteristieke stempel van die Engels-georiënteerde kultuur wat aan die Witwatersrand gevestig is. Toonaangewende persoonlikhede uit Engelse geledere is dit met mekaar eens dat die onderwys vir Suid-Afrika nie slegs vanuit ' $n$ Afrikaans-Christelike volkseie lewensopvatting beplan kan word nie (Steyn, 1988:607).

Die gevolg is dat in die opleiding van onderwysers geen eenstemmigheid bestaan oor die beginsels en norme wat ten grondslag daarvan behoort te lê nie. Selfs waar saamgestem word dat die onderwys op 'n Christelike grondslag moet geskied, is probleme. Hierdie onsekerhede verhoed Suid-Afrika om 'n produktiewe en 'n voorspoedige land te word. Die probleem is hoe om die onderwysersopleiding in Suid-Afrika so te verbeter dat die volgende geslag 'n hoër lewenskwaliteit kan hê (Jacobs, 1991:241-243).

Ouers kan deesdae die gees en rigting van 'n skool bepaal. Indien hulle Christelike onderwys op prys stel, behoort hulle aandag te skenk aan goeie onderwysersopleiding, die ontwerp van leerplanne en die skrywe van geskikte handboeke om die ideaal van Christelike vakonderwys te verseker (Van der Linde, 1992:2). 


\section{Die verhouding tussen die kerk en die skool}

Die band van die ware geloof in die enigste, waaragtige Saligmaker Jesus Christus, bind die gelowiges saam in die liggaam van Christus, naamlik die kerk. In die genadeverbond eis die Here van die gelowige geloof, nuwe gehoorsaamheid en bekering. Hierdie verbond word na sy ryke belofte in die heilige doop beseël en bekragtig. In die heilige doop verlang die Here van die gelowiges ' $n$ belofte dat aan die eis van die verbond voldoen sal word deur middel van die onderrig aan en die opvoeding van die kind in en ooreenkomstig die waaragtige leer van die saligheid. Hierdie onderwys moet deur die ouers gegee word. Voorts moet die ouers hierdie onderwys ook aan hulle kinders láát gee. In hierdie woorde en in hierdie belofte lê die beginsel van Christelike onderwys in 'n Christelike skool opgesluit.

Die ampte en vergaderinge van die kerke het 'n uiters belangrike taak betreffende die skool, naamlik die handhawing van die eis van die genadeverbond by die ouers en die onderwysers. Die kerkrade moet toesien dat onderwysers in hulle verantwoordelike arbeid voldoen aan die eis van die verbond ooreenkomstig die leer van die kerke en daarin meewerk om die heelheid van die kinders te bewaar en te beskenn teen enige gebrokenheid, dualisme of neutralisme (K.O., art. 21).

Die roeping van die kerke sluit onder andere die volgende in:

* Die bearbeiding van die ouers deur prediking, huisbesoek, geskrifte en voorligting om hulle op te skerp tot die handhawing van die doopsbeloftes en tot georganiseerde optrede ter verkryging van skole wat voldoen aan die eis van die kerke ten opsigte van die skole.

* Die raadpleging met bevoegde gereformeerde opvoedkundiges met die oog op die opvoedkundig-verantwoorde sistematisering van die beginsels rondom die onderwysstelsel en die skole in die lig van en ooreenkomstig die eise van die kerke en die ouers.

Met die volgende moet rekening gehou word:

Die onderwysers word deur die ouers gekies, gee onderwys ooreenkomstig die eise van die ouers en die wense van die owerheid, is verantwoordelik vir die interne aangeleenthede van die skool, bepaal die vakinhoud en gee leiding in alle opvoedkundige sake (Deputate, 1967:555-560).

\section{Samevatting}

Artikel 21 van die Kerkorde van die Gereformeerde Kerke behoort nie net na die skoolonderwys te verwys nie maar ook na die onderwys in 'n breër verband om byvoorbeeld die tersiêre onderwys in te sluit. Daar behoort nie net oor die ver- 
antwoordelikhede van die ouers gehandel te word nie maar ook oor die verantwoordelikheid van onderwysers en dosente.

\section{Bibliografie}

BARNARD, M.C. 1992. Ek is ' $n$ ouer help my. Roeping en Riglyne, 40(4):3,5,6, Des

DEPUTATE, 1967. Handelinge van die ses-en-dertigste sinodale vergadering van die Gereformeerde Kerk in Suid-Afrika. Potchefstroom : Potchefstroom Herald.

DRECKMEYR, M. 1992. Die onderwyser as lewende kurrikulum in ons skole. Kurr-ikomm, 18(3):11-12, Jul.-Sept.

DU TOIT, J.D 1911. Bethelsdorp, of de eerste beginselen van de Zuid-Afrikaanse zending (In Hamersma, T., Los, S.O., Du Toit, J.D. De geschiedenis van de Christelike kerk. Potchefstroom : Het Westen-Drukkerij. 297-312.)

DU TOIT, J.D. \& SPOELSTRA, T.T. 1945. Kerkorde van die Gereformeerde Gemeentes in Suid-Afrika Pretoria : Ven R-Drukkery.

GOUWS, M. 1992. Die inskerping van Christelike lewenswaardes en norme in die Aardrykskundeklas. Kurr-i-komm 18(3):10, Apr.-Jun.

HENNING, O.A. 1991. Die betekenis van konsepte in die opvoedkunde met verwysing na standpuntverskille aangaande die skool en ouerhuis as gesagstrukture. Koers, 56(2) 229240 , Jun.

JACOBS, M. 1991. Problematic Ideologies in Teacher Education Koers, 56(2):241-258, Jun.

JOOSTE, J.P 1958. Die geskiedenis van die Gereformeerde Kerk in Suid-Afrika, 1859-1959. Potchefstroom : Potchefstroom Herald

LOS, S. O. 1911. Het na-Dordtse tijdvak. (In Hamersma, T, Los, S.O, Du Toit, J D De geschiedenis van de Christelike Kerk. Potchefstroom : Het Westen-Drukkerij. p 205209.)

POSTMA, F. 1935. Christelik-nasionale onderwys in Suid-Afrika. (In Stoker, H G \& Potgieter, F.J.M red Koers in die krisis. Pro Ecclesia-Drukkery : Stellenbosch p. 311 322.)

POSTMA, W. 1987. Parent-Teacher Contact: a Problematic Matter Koers, 53(3) 252-272, Sept

STEYN, I.N. 1987. Kurrikulumnavorsing vanuit Christelik-opvoedkundige perspektief. Koers, 57(2):135-148

STEYN, J. 1988. Die religieus kulturele leefwyse as uitgangspunt van onderwysbeplanning Koers, 53(4):600-612, Des

VAN DELLEN, S. \& MONSMA, M. 1969. The Revised Church Order Commentary Grand Rapids : Zondervan.

VAN DER LINDE, H.J. 1992 Christelike onderwys in die nuwe Suid-Afrika. Lesse vanuit Noord-Amerika Roeping en Riglyne, 40(4):213, Des

VAN DER WALT, J.L. 1990. Christelike onderwys in die praktyk. 'n Evaluering van die huidige stand van sake. Koers, 55(2):247-257, Jun.

VAN DER WALT, J.L. 1992. The Culturo-Historical and Personal Circumstances of Some 19th-Century Missionaries Teaching in South Africa. Koers, 57(1):75-85, March

VAN JAARSVELD, F.A 1984. Omstrede Suid-Afrikaanse verlede Johannesburg : Perskor. 